Oñati Socio-legal Series, v. 9, n. 4 (2019) - La institucionalización de la mediación: potencialidades y riesgos

ISSN: 2079-5971

\title{
La percepción de los equipos de justicia restaurativa del servicio de mediación intrajudicial de Euskadi sobre el protocolo de funcionamiento \\ (The perception of the restorative justice teams of the Basque intra- judicial mediation service on the operating protocol)
}

Alberto josé Olalde Altarejos*

Olalde Altarejos, A.J., 2018. La percepción de los equipos de justicia restaurativa del servicio de mediación intrajudicial de Euskadi sobre el protocolo de funcionamiento. Received 29 October 2018, Accepted 03 December 2018. Oñati Socio-legal Series [online], 9(4), 494-518. Available from: https://doi.org/10.35295/osls.iis//0000-0000-0000-1092

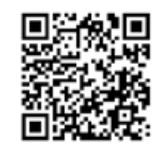

\section{Resumen}

Este trabajo analiza la percepción de los equipos de justicia restaurativa de Euskadi en sede judicial ante el protocolo de funcionamiento del Servicio de Mediación Intrajudicial de Euskadi en el procedimiento de mediación penal. Mediante un estudio cualitativo y grupal por territorios (Araba, Gipuzkoa y Bizkaia), se abordan la definición, los sentimientos, los beneficios, las dificultades y riesgos y las nuevas propuestas que realizan las personas facilitadoras de dicho servicio para la reforma de dicho protocolo.

\section{Palabras clave}

Justicia restaurativa; jurisdicción penal; protocolo; procesos restaurativos; personas facilitadoras

\begin{abstract}
This paper analyzes the perception of the restorative justice teams in judicial settings in Basque Country about the operating protocol of the Intrajudicial Mediation Service of Basque Country in the penal mediation procedure. Through a qualitative and group study by territories (Araba, Gipuzkoa and Bizkaia), the definition, the feelings, the benefits, the difficulties and risks about the operating protocol are addressed. The research project also studies the new proposals made by the facilitators on the reform of the protocol.
\end{abstract}

\footnotetext{
Este trabajo de investigación ha sido financiado por la Dirección de Justicia del Departamento de Trabajo y Justicia del Gobierno Vasco dentro del proyecto de investigación para la Renovación de los protocolos de funcionamiento del servicio de mediación intrajudicial de Euskadi 2017.

* Trabajador Social, Máster en Criminología y Máster Europeo en Mediación. Mediador registrado en el Ministerio de Justicia de España y mediador familiar inscrito en el Registro de Personas Mediadoras del Gobierno Vasco. Doctor en Intervención Social y Mediación por la Universidad de Murcia. Ha trabajado ocho años como mediador en servicios públicos de mediación familiar y penal del Gobierno Vasco. Ha participado como facilitador de encuentros restaurativos en victimización terrorista. Es Profesor Colaborador de la Facultad de Relaciones Laborales y Trabajo Social de la Universidad del País Vasco/Euskal Herriko Unibertsitatea. Dirección postal: Calle Los Apraiz 2, 01006 Vitoria-Gasteiz; correo electrónico: albertojose.olalde@ehu.eus ORCID: https://orcid.org/0000-0001-8899-4166
}

\section{(cc) BY-NC-ND}

Oñati International Institute for the Sociology of Law Antigua Universidad s/n - Apdo.28 20560 Oñati - Gipuzkoa - Spain 


\section{Key words}

Restorative justice; criminal jurisdiction; protocol; restorative processes; facilitators 


\section{Í ndice / Table of contents}

1. Breve introducción conceptual a la justicia restaurativa 497

2. La justicia restaurativa en la Administración de Justicia en Euskadi 498

3. La institucionalización de la justicia restaurativa en Euskadi 501

4. Contexto de la investigación:

el Servicio de Mediación Intrajudicial de Euskadi 502

5. Metodología del estudio 506

6. Resultados 507

6.1. Sombrero blanco: ¿Qué es el protocolo de funcionamiento? ¿Cómo lo definirías? 507

6.2. Sombrero rojo: ¿Cómo te sientes hacia el protocolo? ¿Cómo te hace sentir?.

6.3. Sombrero amarillo: ¿Qué beneficios aporta a tu tarea? ....................508

6.4. Sombrero negro: ¿Cuáles son las dificultades del protocolo? ¿Qué riesgos conlleva para tu práctica? 508

6.5. Sombrero verde: ¿Qué nuevas propuestas harías al protocolo? ¿Qué nuevas ideas incluirías?

6.6. Sombrero azul: ¿Qué acciones, tareas facilitarían un nuevo protocolo? ¿Qué proceso llevarías a cabo para ponerlo en marcha?

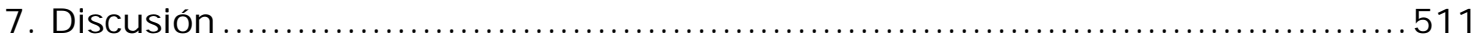

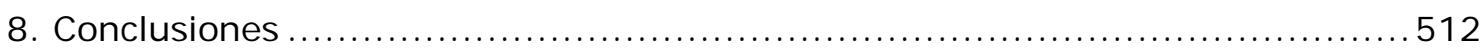

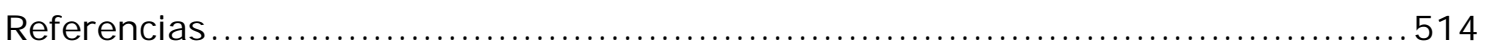




\section{Breve introducción conceptual a la justicia restaurativa}

La justicia restaurativa se entiende como "aquel proceso donde la víctima y el ofensor, y donde sea apropiado, otras personas y miembros de la comunidad afectados por un delito, participan activamente juntos en la resolución de las cuestiones derivadas del mismo, con la ayuda de una persona facilitadora" (Dandurand y Griffiths 2006, p.6).

Reconociendo que el delito causa daños a las personas y comunidades, se insiste en que se reparen esos daños y que a las personas protagonistas de lo ocurrido se les permita participar en ese proceso. Los programas de justicia restaurativa, por consiguiente, habilitan a las víctimas, a la persona infractora y a las personas afectadas de la comunidad para que se involucren de forma directa en dar una respuesta al delito. Ellas llegan a ser el centro del proceso de esta justicia penal, con la ayuda de personas profesionales adecuadas, de un sistema que apunta a la responsabilidad de la persona infractora y a la reparación a las víctimas. Y promueve la total participación de estas últimas, la persona infractora y la comunidad. El proceso restaurador debe involucrar a todas las partes como aspecto fundamental para alcanzar el resultado restaurador de reparación y paz (Zehr 2011).

La mirada de la justicia restaurativa a los conflictos de índole penal suele asociarse con estos tres ejes principales, frente a la justicia retributiva (Zehr 1990):

1. Ve los hechos delictivos en forma más amplia, en vez de defender el delito como mera trasgresión de las leyes, reconoce que las personas infractoras dañan a las víctimas, las comunidades ${ }^{1}$ y a ellas mismas;

2. Involucra más partes en la respuesta al delito, en vez de dar papeles clave solamente al Estado y a la persona infractora, incluye también víctimas y comunidades;

3. Mide en forma diferente el éxito; en vez de medir cuánto castigo debe imponerse, mide cuantos daños deben ser reparados o prevenidos.

Es necesario hacer una distinción, frente a los métodos alternativos de resolución de conflictos (conocidos como ADR), en el sentido que la justicia restaurativa se sitúa en torno a la injusticia y no se muestra moralmente neutra acerca de la misma. La injusticia se define en términos de dominación, por lo que se siente como algo que está mal. Por ello, la justicia restaurativa es una filosofía que rechaza la neutralidad moral de la mediación que define todo en términos de lenguaje moralmente neutral de conflicto (Braithwaite 2003). ${ }^{2}$

Para la justicia restaurativa, la reparación es una oportunidad de participación, activa y directa, por parte de todas las personas afectadas por el delito, incluida la comunidad (McGill 2017). Este enfoque permite una lectura más completa del delito, pues tiene en cuenta las necesidades y la perspectiva de cada uno de los integrantes del conflicto: autor, víctima ${ }^{3}$ y comunidad (Subijana Zunzunegui 2012, Vega Dueñas y Olalde Altarejos 2018).

\footnotetext{
${ }^{1}$ La participación de la comunidad es un asunto crítico que requiere abandonar planteamientos románticos sobre la existencia de un ideal de comunidad marcada por relaciones de equidad, donde las personas son amigables y bien intencionadas. Se advierte el riesgo de que las intervenciones restaurativas puedan terminar reproduciendo diferencias de poder y estatus preexistentes en la comunidad (Rosenblatt 2014). ${ }^{2}$ De hecho, esta tendencia a mirar al conflicto con lentes de neutralidad y de mediación puede provocar un efecto perverso al asociar este tipo de mediación con la negociación de los conflictos y confundir a la sociedad. El delito no es negociable, por lo que el objetivo es el diálogo. Por ello, la mediación víctimaofensor puede verse como un término equivocado por hacer solo referencia al espacio privado entre persona víctima y ofensora (Cutrona 2014). Este paradigma de justicia promueve un sentido comunitario de justicia, de construcción de paz, dando lugar a la voz y participación de la comunidad y la víctima en responder a las consecuencias del delito.

${ }^{3}$ De la mano de este enfoque restaurativo, merece la pena destacar la definición de víctima realizada por Beristain (1998, p. 79). Para este autor, víctima es "además del sujeto pasivo de la infracción, todas las personas físicas o jurídicas que directamente sufren daño notable como consecuencia inmediata o mediata de la infracción".
} 
De esta manera, a diferencia de los modelos tradicionales que se han construido teniendo como base la autoridad de la ley, la seguridad de la sociedad y la educación del culpable (Mate 2003), la justicia restaurativa tiene como base la singularidad y la memoria de las víctimas (Sampedro-Arrubla 2010).

Es preciso entender la justicia restaurativa como un paradigma vinculado a valores. Se distinguen los valores procesales de los valores personales. ${ }^{4}$ Los primeros se vinculan con el respeto, la dignidad individual, la inclusión, la responsabilidad, la seguridad, la promoción de la recuperación y curación, la humildad, el cuidado mutuo, la reparación, la ausencia de dominación etc. Los segundos nos hablan de respeto, honestidad, responsabilidad, compasión, apertura de mente y paciencia.

Para Casado Coronas (2008), los valores de la justicia restaurativa incluyen los siguientes elementos:

- Encuentro: comunicación, narración, emociones-sentimientos y comprensión;

- Reparación: disculpas, cambios de comportamiento y restituciones;

- Reintegración: atención y ayuda a la persona víctima, acogida de la persona infractora;

- Inclusión: facilitación de la información, invitación a personas actoras afectadas a diferente nivel, dando cabida a diferentes tipos de necesidades, flexibilidad en la metodología.

\section{La justicia restaurativa en la Administración de Justicia en Euskadi}

Los primeros servicios públicos de naturaleza restaurativa se implantaron en Euskadi en 2007, ${ }^{5}$ con la denominación de Servicios de Mediación Penal (en adelante SMP), dependiente de la entonces Dirección de Ejecución Penal, como experiencia piloto en los partidos judiciales de Barakaldo y de Vitoria-Gasteiz. Dicha experiencia se extendió posteriormente a los de Bilbao y Donostia-San Sebastián durante los años 2008 y 2009, estando consolidado el Servicio de Mediación Penal en los cuatro partidos judiciales referidos en 2010.

A nivel estatal ${ }^{6}$ sin embargo, no es hasta el año 2013 que llega la publicación del protocolo de mediación del Consejo General del Poder Judicial (en adelante, CGPJ), dando valor y lugar procesal a la justicia restaurativa. ${ }^{7}$

En este sentido, los esfuerzos por el desarrollo de la mediación en el ámbito judicial, han llevado al CGPJ a publicar la Guía para la práctica de la mediación intrajudicial, donde se hace referencia expresa a la incardinación y organización de la mediación penal (Consejo General del Poder Judicial 2013):

\footnotetext{
${ }^{4}$ También se distinguen entre valores normativos (responsabilidad activa, vida social pacífica, respeto solidaridad) y valores operacionales (reparaciones, asistencia, colaboración, empoderamiento, encuentro, inclusión, educación moral, protección y resolución) [Van Ness 2005].

${ }^{5}$ La primera década del 2000 en España ha supuesto la puesta en marcha generalizada de proyectos de justicia restaurativa y mediación penal, mayoritariamente asociados a delitos y faltas menos graves. Su desarrollo y vertiginoso crecimiento ha sido señalado por Sáez Valcárcel (2011, p. 71), afirmando que "el fenómeno de la mediación penal en España ha desbordado toda previsión". El éxito de dichas experiencias ha sido ya ampliamente estudiado (Varona Martínez, 2008, 2009, Sáez Rodríguez 2011).

${ }^{6}$ Se percibe que las "Iimitaciones del principio de oportunidad en nuestro sistema procesal penal han determinado que la mediación penal de adultos y otras prácticas restaurativas como el conferencing hayan tenido un menor arraigo en España que en otros países europeos" (García Herrera 2015, p. 1).

7 Cfr. Consejo General del Poder Judicial 2013. Durante este año, de acuerdo a datos facilitados por el Consejo General del Poder Judicial, se derivaron 3.984 mediaciones penales (frente a las 2.728 del año 2012). Si atendemos a las memorias del Gobierno Vasco y la Generalitat de Catalunya, observamos que durante el año 2013 se derivaron en dichas comunidades autónomas, 1.619 y 1.236 casos respectivamente, lo cual entre ambas comunidades supone un $71 \%$ del total de las derivaciones en España. Fuente: Departamento de Administración Pública y Justicia del Gobierno Vasco (2014) y fuentes consultadas del Programa de Mediación y Reparación Penal de la Dirección General de Ejecución Penal a la Comunidad y de Justicia Juvenil de la Generalitat de Catalunya.
} 
- Desarrolla recomendaciones para la implementación e incardinación de los procedimientos de mediación dentro de la legislación penal vigente, explicando los protocolos de derivación a mediación según las diferentes fases del proceso penal;

- Promueve la homogeneización a nivel territorial de la implantación de la mediación dentro del proceso penal vigente;

- Explica los beneficios que conlleva devolver a la sociedad civil la responsabilidad en la resolución de sus conflictos;

- Explica las fases procesales para la derivación y las recomendaciones para la misma para el Juzgado. I gualmente propone un test diagnóstico de casos mediables atendiendo a las condiciones de marco jurídico y de procedimiento, de idoneidad del conflicto, de buena voluntad en las partes y de los beneficios de la mediación;

- Propone fichas estadísticas para la recogida homogénea de datos de los expedientes derivados a mediación penal y de información sobre la satisfacción de personas usuarias;

- Desarrolla los principios que protegen su implantación de eventuales riesgos y excesos: voluntariedad de las partes, gratuidad, confidencialidad, oficialidad, flexibilidad y bilateralidad.

Para la puesta en marcha de la experiencia en Euskadi en julio de 2007, se elaboró un Protocolo de Mediación Penal en consenso con los operadores jurídicos. Su objetivo era regular pormenorizadamente el funcionamiento de los SMP en sus relaciones con los órganos judiciales para la derivación de asuntos, así como para la eficacia de los acuerdos de mediación sobre el procedimiento penal. Era una labor necesaria entonces, ${ }^{8}$ debido no solamente a la falta de regulación legal específica de ámbito estatal sobre la materia de mediación, tanto en el Código penal como en la legislación procesal, sino también por tratarse de la primera vez que de forma sistemática, con pretensiones de generalizarse y desde la iniciativa de la administración pública, se iba a introducir una fórmula alternativa de resolución de conflictos - complementaria e incardinada dentro de la Administración de Justicia- en Euskadi.

Una vez asentado el SMP en la Administración de Justicia en Euskadi, en 2011 se transformó en el Servicio de Mediación Intrajudicial (en adelante SMI), a fin de extender su actuación a otras jurisdicciones y ámbitos de actuación donde la mediación tuviese cabida como fórmula alternativa para la resolución de conflictos. Asimismo, se amplió el servicio a todos los partidos judiciales para que estuviera al alcance de toda la ciudadanía, con ánimo tendencial a la configuración como derecho de la ciudadanía.

A fin de clarificar las diferentes actuaciones y para ordenar el funcionamiento de estos y sus relaciones con los órganos judiciales, Ministerio Fiscal y resto de operadores jurídicos y ciudadanía que pudieran estar afectados, en 2012 se redactaron los últimos protocolos de funcionamiento del Servicio de Mediación Intrajudicial hasta el momento que incluían el ámbito penal y el de mediación familiar intrajudicial. ${ }^{9}$

Las experiencias de justicia restaurativa en España parten de un "pecado original": la ausencia de un marco legal que les dé cauce. ${ }^{10}$ Desafortunadamente, desde 2012 hasta la actualidad, las únicas novedades legislativas sustantivas o procesales

\footnotetext{
${ }^{8}$ Véanse en este sentido las críticas de Richards (2014) sobre el vínculo que se va construyendo entre los sistemas de justicia penal y los de justicia restaurativa, por los intentos de éste último en abordar los problemas identificados dentro del sistema penal. O las de Maglione (2018, p. 21) al señalar que "el proceso de incorporar la justicia restaurativa en los marcos legales se equipara con la transformación de la justicia restaurativa en un mecanismo de justicia soberana que limita la creatividad, produce control y respalda las relaciones jerárquicas".

${ }^{9}$ Nuestro artículo se centra exclusivamente en el ámbito penal.

${ }_{10}$ Véase en ese sentido la intervención de la Comisión para la Eficiencia de la Justicia (CEPEJ 2007) ante la muy diferente disponibilidad y el desigual conocimiento en Europa de la mediación en el ámbito penal.
} 
atinentes a justicia restaurativa han sido el nuevo artículo 84 del Código penal cumplimiento del acuerdo de mediación como condición de la suspensión de la ejecución de la pena privativa de libertad- y el reconocimiento de la existencia de la figura de la persona mediadora al tipificarla como nuevo posible sujeto activo del delito de cohecho (artículo 423). Con ello continúa el extraño desarrollo legislativo de la materia que comenzó con el art. 87 ter.5 Ley Orgánica del Poder Judicial (LOPJ) - que prohibía lo que legalmente no existía-, ahora previendo un efecto y las responsabilidades de una figura, la de la persona mediadora, cuya existencia, procedimiento y funciones aún no son una realidad legal. ${ }^{11}$

Esta situación de déficit normativo hace imprescindible la adopción de acuerdos de funcionamiento, que es lo que llamamos protocolo. Acuerdo que necesita ser consensuado y respetado por los actores en materia de justicia restaurativa, a saber, órganos judiciales, ministerio fiscal, letrados y letradas de la Administración de J usticia, servicios de justicia restaurativa y letrados y letradas de las partes. Sin duda, el "verdadero protocolo", el que oriente mediante vinculación legal la actuación de estos actores, será la reforma legal que prevea la creación de servicios de justicia restaurativa, la derivación de los asuntos y la incorporación al proceso penal de los acuerdos restaurativos y sus efectos sobre la responsabilidad penal y civil.

En consecuencia, los más importantes hitos legislativos en la materia en nuestro país en este periodo es el Estatuto de la Víctima del Delito y la Directiva 2012/29/UE del Parlamento Europeo y del Consejo, de 25 de octubre de 2012, por la que se establecen normas mínimas sobre los derechos, el apoyo y la protección de las víctimas de delitos, de la que trae causa. Si bien es cierto que establece una regulación no esencial sino tangencial, lo más relevante a nuestro juicio es que expresa un cambio de paradigma en el ámbito de la justicia restaurativa, que también se observa en el ámbito de lege ferenda de enjuiciamiento criminal.

Tradicionalmente en la justicia restaurativa han convergido varias tendencias y modelos:

1. El que mira a la persona infractora (como alternativa a la pena relacionada con el principio de oportunidad en el ejercicio de la acción penal);

2. El que mira a la Administración de Justicia (para la agilización y descarga de trabajo, como se expresa en la Guía Práctica de la Mediación Intrajudicial aprobada por el CGPJ); y

3. El que mira a la víctima (como método de participación y reparación material y moral).

El Estatuto de la Víctima del Delito ha invertido la tendencia tradicional preeminente anteriormente en la iniciativa legislativa ${ }^{12}$ y de los operadores jurídicos españoles en las experiencias desarrolladas en las últimas dos décadas: un paradigma centrado en la persona infractora, en el principio de oportunidad y en su comprensión como instrumento de renuncia o aminoración de la pena. Y como consecuencia de ello, se ha primado la delincuencia de bagatela como ámbito en el que es aplicable un sistema alternativo de responsabilidad penal. Un espacio complementario al procedimiento penal en cuanto no adversarial, al habilitar un espacio de comunicación interpersonal dentro del proceso penal, que incide en la disminución de la responsabilización penal.

Con la Directiva 2012/29/UE y el Estatuto de la Víctima del Delito, el paradigma gira hacia la preeminencia del interés de la víctima. ${ }^{13}$ Una consecuencia, entre otras, a

\footnotetext{
${ }^{11}$ La flexibilidad en la reglamentación de la justicia restaurativa es necesaria y requiere de la introducción de elementos que respeten la idiosincrasia de los procesos restaurativos (Gaddi 2018).

${ }^{12}$ Así, el Anteproyecto de Ley de Enjuiciamiento Criminal de 2011 (véase el apartado XXVI de la Exposición de Motivos, titulado Principio de oportunidad y mediación, y sus arts. 157-161 y 701) comprende la institución de la mediación en el marco del principio de oportunidad y la renuncia a la imposición de la pena, esto es, orientando la aplicación de la mediación al beneficio penológico para el infractor, con lo que los beneficios para la víctima quedan en un segundo nivel.

${ }^{13}$ Véase algunas consideraciones críticas al Estatuto, como la falta de incardinación de la mediación en el proceso (Castañón Álvarez y Solar Calvo 2016).
} 
nuestro juicio clara, es que los procesos de justicia restaurativa deben desplazarse desde la delincuencia de bagatela hacia la delincuencia de mayor gravedad y significación para la víctima. También que en la derivación éste ha de ser el principal criterio, antes que los intereses del victimario o de la propia Administración de Justicia.

Este cambio de paradigma se trasladó ya a la propuesta de texto articulado de Ley de Enjuiciamiento Criminal, Código Procesal Penal, de 2013, elaborada por la Comisión Institucional creada por acuerdo del Consejo de Ministros de 2 de marzo de 2012 (véase apartado IV de su Exposición de Motivos y sus arts. 143 a 146) - ya tras la Directiva 2012/29/UE del Parlamento Europeo y del Consejo de 25 de octubreque conceptualizaba la mediación penal en primer lugar como un "mecanismo de solución del conflicto entre infractor y víctima que satisfaga las expectativas de la víctima de obtener una explicación del hecho, la petición de perdón y una pronta reparación". Así:

la justicia restaurativa se concibe no como sustitutivo de los tradicionales fines de la justicia penal, sino como complemento necesario del que deben extraerse todas sus capacidades sin dejarlo vinculado al principio de oportunidad o al instituto de la conformidad, lo que supone una visión estrecha de la mediación, o a criterios utilitaristas o a la delincuencia menor. Ni toda mediación ha de acabar en la aplicación del principio de oportunidad o una conformidad, ni estas reclaman necesariamente una mediación previa. En la justicia restaurativa la víctima, siempre voluntariamente, adquiere un singular protagonismo. (Ministerio de Justicia de España 2013, p. 7)

En este contexto se ha realizado un estudio que a continuación se presenta, sobre cómo perciben dicho protocolo de funcionamiento los facilitadores y facilitadoras de los equipos de Araba, Bizkaia y Gipuzkoa del Servicio de Mediación Intrajudicial de Euskadi. Todo ello, con el objetivo de realizar una evaluación sobre el mismo, así como realizar propuestas de mejora de cara al nuevo Protocolo de Justicia Restaurativa que se pone en marcha a finales del año 2018.

\section{La institucionalización de la justicia restaurativa en Euskadi}

El Departamento de Justicia del Gobierno Vasco ostenta, conforme a los artículos 11.1.b y 14.d del Decreto 84/2017, de 11 de abril, por el que se establece la estructura orgánica y funcional del Departamento de Trabajo y Justicia, competencia para "proveer, en general, de medios personales y materiales necesarios para el funcionamiento de la Administración de Justicia", transferida al amparo del artículo 150 de la Constitución y artículos 13 y 35.3 del Estatuto de Autonomía, y "fomentar y desarrollar la Justicia Restaurativa y la resolución alternativa de conflictos en el marco de la Administración de Justicia".

En este marco, el Departamento de Justicia puso a disposición de los órganos judiciales de la Comunidad Autónoma los Servicios de Mediación Penal, luego Servicios de Mediación Intrajudicial, para finalmente optar en el año 2018 por el nombre de Servicio de Justicia Restaurativa (Departamento de Trabajo y Justicia del Gobierno Vasco 2018).

En el marco de sus respectivas competencias y "para el impulso de la mediación y de otras formas de resolución pacífica de conflictos y de justicia restaurativa como fórmula alternativa y/o complementaria al proceso judicial", el 27 de abril de 2015 el CGPJ y el Gobierno Vasco suscribieron un Acuerdo de colaboración. En él ambas partes adquirieron importantes obligaciones mutuas para el desarrollo de la mediación, la justicia restaurativa y formas pacíficas de resolución de conflictos en el ámbito de la Administración de Justicia en Euskadi. A grandes rasgos, el Gobierno Vasco se compromete a proporcionar los medios personales, organizativos y materiales necesarios para el desarrollo de la justicia restaurativa y la resolución pacífica de conflictos, mantener informado al CGPJ y formar a los empleados y empleadas públicas al servicio de la Administración de Justicia. Por su parte, el CGPJ se compromete a dar a conocer la mediación y otras formas de resolución pacífica de 
conflictos y de justicia restaurativa entre los y las jueces y magistrados en Euskadi, en lo que juegan un papel relevante el Gabinete Técnico del CGPJ y el Servicio de Inspección, así como recabar información de la Dirección de Justicia, de los Servicios y de los órganos judiciales.

A nuestro juicio, este acuerdo constituye un elemento esencial que habría de contribuir a la asunción por los órganos judiciales de la justicia restaurativa y sus diferentes procesos restaurativos (mediación víctima-persona ofensora, conferencias, círculos, paneles, etc.) como un sistema a su disposición, así como a su extensión y su desarrollo uniforme.

En este marco cobra especial relevancia la Guía Práctica de la Mediación Intrajudicial aprobada por el CGPJ en 2016 (http://www.poderjudicial.es/ cgpj/es/Temas/Mediacion) "para que los jueces y juezas puedan ejercer la jurisdicción haciendo un uso apropiado de esta herramienta" con el "compromiso activo y conjunto de la judicatura y de los colectivos que participan en la Administración de Justicia". ${ }^{14}$

Por otro lado, el entonces Fiscal General del Estado, Excmo. Sr. Eduardo Torres-Dulce Lifante, por Decreto de 25 de mayo de 2012, autorizó, en virtud del artículo 11.3 del Estatuto Orgánico del Ministerio Fiscal, la firma del Protocolo de Mediación Penal Intrajudicial en la Comunidad Autónoma del País Vasco, lo cual constituye a nuestro juicio otro elemento de gran relevancia para dotar a la misma de oficialidad y su asunción por el Ministerio Público como un sistema a su disposición, así como a su extensión y su desarrollo uniforme, aunque según la información disponible finalmente no se culminara la firma (Etxebarria y Olalde 2018).

También el Acuerdo de Colaboración para la promoción de la mediación entre el CGPJ y la Fiscalía General del Estado, de 25 de mayo de 2016, para promover el uso de la mediación en los procesos judiciales entabladas al efecto en todos los órdenes jurisdiccionales, compartiendo la apuesta por un modelo de Administración de Justicia que incorpore plenamente la mediación y cualesquiera otros sistemas de resolución pacífica de conflictos, constituye un elemento de oficialidad relevante.

\section{Contexto de la investigación: el Servicio de Mediación Intrajudicial de Euskadi}

El Servicio de Mediación Intrajudicial de Euskadi es el lugar donde nuestro trabajo de investigación se contextualiza. ${ }^{15}$ Dicho servicio atiende los 14 partidos judiciales de la Comunidad Autónoma del País Vasco con equipos multidisciplinares que desarrollan su tarea profesional en procesos restaurativos y procedimientos de mediación familiar intrajudicial, bajo la fórmula de Convenio de Colaboración con la Asociación sin ánimo de lucro Adosten. ${ }^{16}$

El servicio, desde sus inicios hasta finales del año 2017, atendió la derivación de 11.684 casos desde los diferentes órganos judiciales.

Veamos a continuación la evolución de la derivación de casos de justicia restaurativa en los tres territorios:

\footnotetext{
${ }^{14}$ Véase en este sentido la aportación de Subijana, Porres y Sánchez (2015).

${ }^{15}$ Nos centramos únicamente en la tarea de justicia restaurativa de los equipos del Servicio de Mediación Intrajudicial de Euskadi, que convive con la de mediación familiar intrajudicial, quedando ésta última al margen de este artículo.

${ }^{16}$ Adjudicado a IRSE (Instituto de Reintegración Social de Euskadi) en mayo de 2018 (Departamento de Trabajo y Justicia del Gobierno Vasco 2018).
} 
CUADRO 1

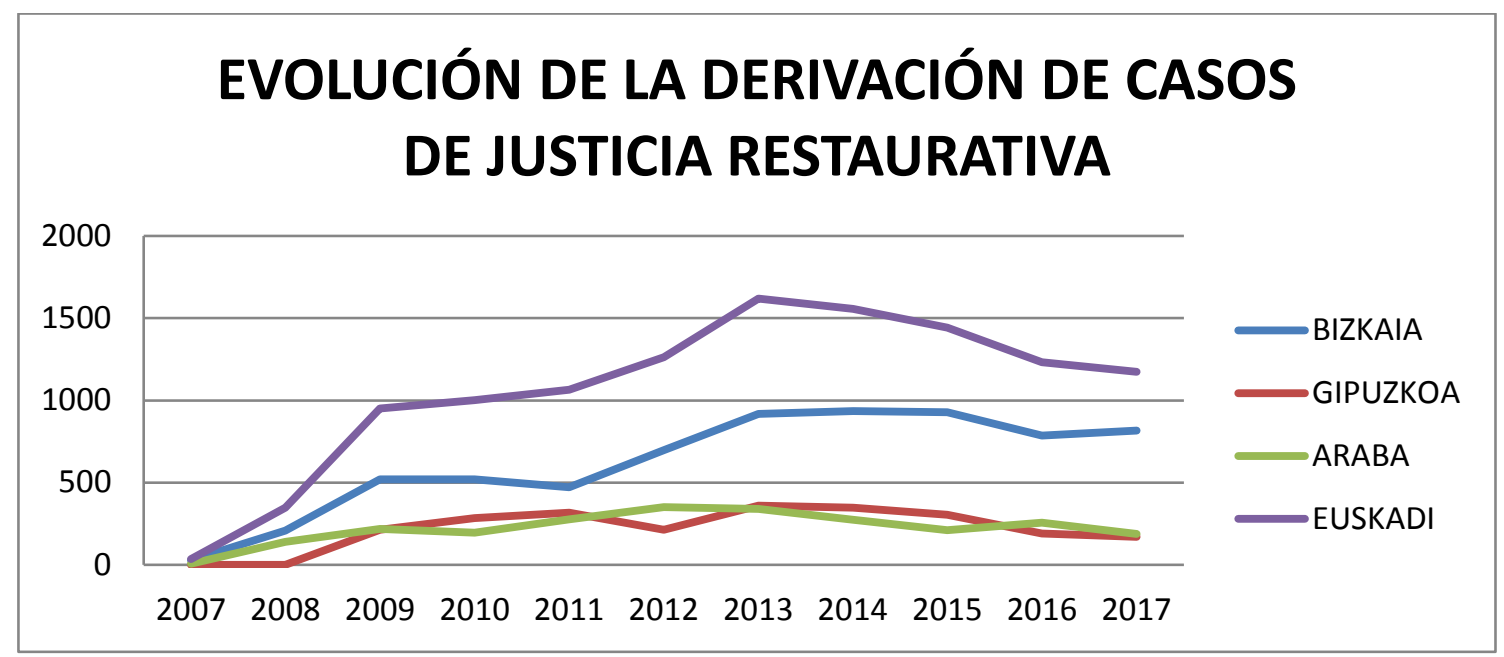

Cuadro 1. Evolución de la derivación de los casos de justicia restaurativa. (Fuente: elaboración propia.)

Se produce una evolución creciente en todos los territorios hasta el año 2011 que comienza el descenso, coincidiendo con la incorporación de casos de mediación familiar. En Bizkaia la reducción de la derivación es llamativa en el año 2014, el 2013 en Gipuzkoa y desde 2010 en Araba, con un ligero repunte en 2016. ${ }^{17}$

Podemos destacar, a modo general, los siguientes aspectos del servicio: ${ }^{18}$

- En lo que respecta a la tipología delictiva derivada, se percibe un descenso paulatino de procesos restaurativos en delitos y un aumento de los delitos leves (antiguas faltas). Dicha tipología se desglosa de la siguiente manera, con las siguientes horquillas con porcentaje.

o Delitos graves:

- Lesiones: $60 \%$.

- Estafa: $15 \%$.

- Contra la integridad moral en violencia intrafamiliar: $10 \%$.

- Homicidio: $4 \%$.

- Detención ilegal: $4 \%$.

- Apropiación indebida: $4 \%$.

- Tenencia y depósito de armas, municiones o explosivos: $4 \%$.

o Delitos menos graves:

- Lesiones: 30-40\%.

- Robos con fuerza: $10-15 \%$.

- Lesiones en violencia doméstica/familiar: 10-15\%.

- Daños: 5-10\%.

- Impago de pensiones: 5-10\%.

- Amenazas: 5-10\%.

- Coacciones: 5-10\%.

- Hurtos: 5-10\%.

- Apropiación indebida: 5-10\%.

- Estafa: 5-10\%.

\footnotetext{
17 Las razones de la fluctuación de la derivación exceden el objetivo de este artículo. Los equipos de justicia restaurativa del SMI suelen atribuir estas fluctuaciones a las decisiones arbitrarias de los órganos derivadores.

18 Datos exclusivos de casos derivados en el contexto penal.
} 
o Delitos leves (o faltas):

- Lesiones: 20-30\%.

- Amenazas: $15-20 \%$.

- Incumplimiento de obligaciones familiares: 15-20\%.

- Injurias-vejaciones: 10-15\%.

- Coacciones: 10-15\%.

- Daños: 5-10\%.

- El porcentaje de acuerdos comienza en un $75 \%$, alcanzando un $81 \%$ en el año 2017.

- A lo largo de los once años de estudio, de los casos derivados por los órganos judiciales, se realizan procesos restaurativos en una franja del $60 \%$ al $80 \%$ de los casos.

- En lo relativo a los efectos penológicos de los procesos restaurativos en los procesos judiciales, sin perjuicio de análisis más exhaustivos, podemos destacar que las sentencias judiciales recogidas por los equipos de facilitadores y facilitadoras muestran los siguientes efectos medios tras el proceso restaurativo:

o En faltas:

- Ausencia de sanción penal prácticamente en el $100 \%$.

o En delitos leves:

- Ausencia de sanción penal: $80 \%$.

- Existencia de sanción penal: $20 \%$.

o En delitos menos graves:

- Ausencia de sanción penal: 70\%.

- Existencia de sanción penal: 30\%.

o En delitos graves:

- Ausencia de sanción penal: $45 \%$.

- Existencia de sanción penal: 55\%.

- Los tiempos medios de la intervención de los equipos de mediación son los siguientes:

o Menos de un mes: $40-50 \%$.

o Entre 1 y 2 meses: $25-35 \%$.

o Entre 3 y 6 meses: $10 \%$.

En lo referente a la naturaleza de los acuerdos y resultados restaurativos construidos por las personas participantes, de manera resumida e integrada en los once años, predominan:

- Legal-procesal: 35\% (habitualmente, la renuncia de la parte denunciante a las acciones legales - penales y civiles- que pudieran corresponderle por los hechos denunciados).

- Ética: 30\% (relativo al reconocimiento de la responsabilidad de las personas participantes en el desarrollo de los hechos denunciados; reflexiones verbalizadas relativas a lo inadecuado del comportamiento, a la identificación y reprobación por los daños causados; y traslado y/ o aceptación de disculpas).

- Conductual: 20\% (relativo a la modificación en el comportamiento de las personas, tendente a mejorar su problemática en relación con el conflicto originado).

- Material-económica: 8\% (reparaciones monetarias o patrimoniales).

- Sanitaria: 1\% (compromisos de sometimiento a abordaje psico-sanitario en relación con las dificultades de salud mental y/o de consumo de sustancias tóxicas). 
- Social: 1 \% (compromisos de intervención social).

En lo relativo a la percepción de cumplimiento de acuerdos: ${ }^{19}$

- De los datos obtenidos se observa una percepción de que el acuerdo se ha cumplido totalmente en un $65 \%$ y parcialmente en un $15 \%$.

- En el estudio específico sobre faltas en Álava, la percepción de personas usuarias sobre el cumplimiento total alcanza un $87 \%$ (I gartua et al. 2015)

En lo relativo a la atención recibida:

- En Barakaldo, en el periodo 2007-2010, hay una satisfacción del 70\% con el servicio, una satisfacción alta (\%62) con el proceso restaurativo.

- En Vitoria-Gasteiz es valorada en un $85 \%$ como "muy satisfactoria" y en un 10\% como "bastante satisfactoria" en el año 2008.

A lo largo de estos 11 años observamos un volumen de derivación de casos que alcanza los 11.684 casos. Una cifra muy respetable, a tenor de lo que ocurre en el resto de España. La derivación de los órganos judiciales es muy desigual, existen juzgados que derivan con normalidad y continuidad, algunos juzgados que nunca derivan y otros que cambian de dinámica a lo largo de los años, muchas veces por cambios de juez o jueza. Podemos observar que el volumen de casos nos invita al optimismo y a constatar la aceptación del sistema de justicia restaurativa en el sistema de justicia penal. Sin embargo, la percepción de las personas facilitadoras es que existe todavía mucho desconocimiento y confusión sobre las características de los procesos restaurativos y sus eventuales beneficios, como veremos luego.

El encaje jurídico de los acuerdos y la disparidad de criterios a la hora de aplicar atenuantes $u$ otras repercusiones penológicas se constituye como un elemento de crucial importancia. Ello da valor al proceso de responsabilización de la persona ofensora y al reproche humano y social que puede suponer la toma de conciencia del daño en un proceso restaurativo. ${ }^{20}$

Es notorio el descenso de la derivación de casos penalmente graves y una tendencia hacia las infracciones leves, lo cual nos hace pensar en el desconocimiento, minusvaloración o desconfianza que pudieran tener los órganos judiciales en los beneficios de la justicia restaurativa para las víctimas de delitos de mayor gravedad, o quizás, la dificultad de encajar procesalmente los acuerdos entre las partes. ${ }^{21}$

La implantación de un sistema novedoso de justicia como es el restaurativo, un paradigma nuevo, dentro de un sistema que sigue juzgando con procedimientos procesales dirigidos casi en exclusiva a la averiguación del delito y del delincuente y que mantiene la preeminencia de la finalidad punitiva es un constante reto que debe afrontarse con respeto, comunicación y mucho diálogo. Pero la integración de la reparación, protección y satisfacción de la víctima en este sistema es un camino ya sin vuelta atrás, como se regula en el Estatuto de la Víctima del Delito.

El número de casos derivados, el alto porcentaje de asuntos que han alcanzado acuerdo restaurativo, así como el alto grado de satisfacción de las personas participantes, allá donde se ha podido conocer, y el alto cumplimiento de los acuerdos, nos permite valorar globalmente de manera positiva estos once años. Sin embargo, la inercia burocrática, las peculiaridades del sistema penal con sus lógicas

\footnotetext{
19 Nos referimos a cómo lo perciben subjetivamente las personas participantes entrevistadas al efecto, cuya información aparece en las diferentes memorias de los servicios objeto de esta investigación (Administración de Justicia en Euskadi 2008-2017).

${ }^{20}$ Véase en este caso la tesis doctoral que analiza este fenómeno en profundidad: I gartua 2015.

21 A pesar de las evidencias empíricas, que sobre los beneficios de la justicia restaurativa en asuntos graves comienzan a aflorar en la literatura científica. Destacamos la superación de síntomas del trastorno por estrés postraumático en víctimas, cambios emocionales y actitudinales de victimarios hacia la empatía a víctimas, así como efectos en el desistimiento y reincidencia delictiva. Véase en ese sentido la tesis doctoral de David L. Gustafson (2018).
} 
punitivas y los retos procesales para encajar jurídicamente los acuerdos restaurativos son, entre otros, importantes temas que deberán abordarse en los próximos años para que los procesos restaurativos alcancen una mayor y mejor presencia.

Por último, podemos destacar la variedad y creatividad de acuerdos restaurativos, donde los acuerdos económicos tienden a quedarse en un segundo lugar, primando las reparaciones simbólicas, de contenido moral (disculpas y conciliación) y los compromisos y cambios conductuales, muchas veces sostenidos con el acompañamiento del sistema de salud mental y de protección social.

\section{Metodología del estudio}

Para conocer la percepción de los equipos de facilitadores y facilitadoras del Servicio de Mediación Intrajudicial de Euskadi sobre el protocolo de funcionamiento, se han realizado cuatro sesiones de trabajo grupales con los y las profesionales en las sedes de Vitoria-Gasteiz, Donostia-San Sebastián, Bilbao y Barakaldo.

Las sesiones de trabajo realizadas durante el año 2017, se basaron en una sencilla metodología con dos partes: una primera donde las personas entrevistadas respondían por escrito y en silencio a las preguntas propuestas, y creadas ad hoc, a partir de los planteamientos de pensamiento lateral (De Bono 1988); y una segunda, donde las personas entrevistadas tenían la oportunidad de compartir sus pensamientos y dialogar con mayor libertad sobre ellos, buscando puntos comunes y diferencias.

Edward de Bono propone la utilización, de manera simbólica de seis sombreros para pensar, de diferente color, de tal manera que las personas que piensan sobre un fenómeno cambien su forma de pensar, separando el ego del desempeño, explorando temas en paralelo y aumentando la creatividad (De Bono 1988):

- El sombrero blanco nos hace pensar sobre lo que conocemos sobre un fenómeno, la información disponible y los datos que tenemos;

- El sombrero rojo nos interpela sobre los sentimientos sobre un fenómeno, lo que la intuición nos enseña y nuestras reacciones más emocionales;

- El sombrero amarillo nos habla de los beneficios, de las cosas positivas, así como del pensamiento crítico constructivo sobre el fenómeno de estudio;

- El sombrero negro nos advierte de los posibles problemas, de las dificultades que se afrontan, así como los riesgos y las precauciones que han de observarse;

- El sombrero verde nos abre paso a las ideas creativas sobre el fenómeno de estudio, las alternativas de pensamiento que se nos ocurren, así como las nuevas ideas que se proponen; y

- El sombrero azul nos enseña cómo caminar, qué tenemos que tener en cuenta para el cambio, qué agenda debe ponerse en marcha.

De acuerdo a esta estructura de pensamiento lateral, las personas entrevistadas han respondido a las siguientes preguntas, de acuerdo a los diferentes sombreros:

- Sombrero blanco:

- ¿Qué es el protocolo de funcionamiento?

o ¿Cómo lo definirías?

- Sombrero rojo:

o ¿Cómo te sientes hacia el protocolo?

o ¿Cómo te hace sentir?

- Sombrero amarillo:

o ¿Qué beneficios aporta a tu tarea? 
- Sombrero negro:

- ¿Cuáles son las dificultades del protocolo?

- ¿Qué riesgos conlleva para tu práctica?

- Sombrero verde:

- ¿Qué nuevas propuestas harías al protocolo?

o ¿Qué nuevas ideas incluirías?

- Sombrero azul:

- ¿Qué acciones o tareas facilitarían un nuevo protocolo?

- ¿Qué proceso llevarías a cabo para ponerlo en marcha?

La sesión de entrevista grupal se va desarrollando a partir de las preguntas ofrecidas por el guión de este investigador, cuyas respuestas son escritas a mano en tarjetas pequeñas por las personas entrevistadas. Una vez respondidas todas las preguntas, las personas participantes comparten sus respuestas y dialogan sobre las mismas, permitiendo reafirmarse, contrastar y socializar las mismas.

\section{Resultados}

6.1. Sombrero blanco: ¿Qué es el protocolo de funcionamiento? ¿Cómo lo definirías?

Los equipos de profesionales del SMI definen el protocolo de funcionamiento como un procedimiento y normativa que regula su actividad, configurándose como instrumento imprescindible para ordenar, regular y establecer su trabajo dentro del proceso judicial. Como documento consensuado en su momento con Fiscalía y judicatura, permite encajar los procesos restaurativos dentro del proceso judicial. Ofrece garantías, pautas de actuación y es guía y apoyo para la persona facilitadora. Es la hoja de ruta de trabajo de la persona mediadora y supone la regulación oficial de la mediación ante su ausencia.

\subsection{Sombrero rojo: ¿Cómo te sientes hacia el protocolo? ¿Cómo te hace sentir?}

Los equipos de profesionales perciben mayoritariamente el protocolo como un instrumento que ofrece seguridad frente a la intervención con las personas usuarias, recogiendo todo el procedimiento de "qué se debe hacer o no se debe hacer en el servicio". Hace sentirse de alguna manera privilegiadas de poder trabajar con un "paraguas de seguridad" frente a otras comunidades autónomas que carecen del mismo.

En ocasiones hace sentir "rigidez y es necesaria su adaptación continua". Sin perder la flexibilidad y creatividad propia de cada proceso restaurativo y de la persona facilitadora, se señala que "aporta garantías de respeto a unos principios de igualdad mínimos, de estándares mínimos a toda actuación".

Hay quien siente "frustración porque hay operadores jurídicos que ponen trabas a algunos acuerdos alcanzados por las partes", incluso se habla de "soledad" como sentimiento negativo al no poder llevar casos en comediación por el volumen de trabajo.

A veces se percibe que este tipo de normas "olvidan a las personas, sus tiempos y necesidades".

Hay también otros sentimientos negativos vinculados con lo "lejanos que se sienten de los operadores jurídicos por la falta de puentes comunicativos" no previstos en el protocolo o la "sensación de inseguridad por la falta de legalidad" que provoca en ocasiones "boicoteos de la abogacía". 


\subsection{Sombrero amarillo: ¿Qué beneficios aporta a tu tarea?}

Los equipos profesionales perciben que el protocolo "ayuda a que la profesión de mediador esté valorada como un método que funciona", "organiza el trabajo, da respeto a unos estándares de actuación", ofrece "garantías a cierta igualdad en el servicio prestado a la ciudadanía", otorga "profesionalidad, seguridad, orden de actuación, conocimiento de las funciones de cada uno de los agentes que están relacionados con el procedimiento de mediación, clarifica, visibiliza y quita miedo ante una nueva herramienta en la justicia".

Se percibe incluso el protocolo como un instrumento que "ha dado a conocer el trabajo de mediación y a integrarlo en las decisiones de jueces y fiscales".

6.4. Sombrero negro: ¿Cuáles son las dificultades del protocolo? ¿Qué riesgos conlleva para tu práctica?

El número de respuestas en este apartado es mayor y más diverso, por lo que se reproducen comentarios literales:

- La voluntariedad en su cumplimiento puede suponer la vulneración del principio de igualdad y de seguridad jurídica y la deriva del programa, alejándose de los estándares internacionales.

- Paralización de algunos casos de mediación. Por apreciaciones puramente subjetivas de algunos agentes jurídicos que han de dar el visto bueno.

- Criterios subjetivos y estrechez en la derivación.

- Preocupa el aspecto interpretativo del protocolo por parte de jueces y fiscales.

- Ausencia de referencia a un estatuto de la persona facilitadora (formación, experiencia, obligaciones, derechos, consecuencias de incumplimientos de funciones).

- Problema: a veces el tiempo dado es insuficiente porque se señalan juicios antes del plazo de dos meses (incluso en semanas), obligando a actuar de urgencia.

- El modelo de solicitud a instancia de parte que se ofrecen al ciudadano en la página web del Departamento de Justicia se encuentra desfasado.

- Se derivan expedientes que para el Juzgado son un problema.

- Genera inseguridad por ser incompleto y alejado del funcionamiento diario del servicio.

- Ausencia de garantías mínimas, al no tratarse de una norma de carácter obligado, más bien de carácter orientativo, lo que conduce a que cada cual hace lo que mejor le parece.

- El desconocimiento por parte de agentes jurídicos o intervinientes que no entienden que la tarea del servicio está sujeta a normativa.

- Incompleto. No está acorde con la legislación actual (Código Penal y Ley de Enjuiciamiento Criminal) ni con el quehacer diario de los mediadores.

- El tiempo de actuación es escaso (dos meses, más uno de ampliación).

- En otras ocasiones, el tiempo de dos meses (plazo de actuación) es insuficiente porque es un problema localizar a las partes (lleva mucho tiempo) o es un problema muy complejo y se hace necesario utilizar otros tiempos.

- En la estadística del SMI se recoge la influencia que el acuerdo ha tenido en el proceso penal (beneficios penológicos) y hay determinados juzgados que no facilitan la resolución judicial que puso fin al proceso, documento éste donde se refleja el beneficio penal.

- El trabajo administrativo (gestión de citas) abarca una gran parte de la jornada laboral de la persona facilitadora. Los intentos fallidos de llamadas, 
mensajes de teléfono instando al contacto, elaboración de cartas, actas, restando tiempo a su función principal.

- El protocolo no tiene referencias procesales penales. No habla de caducidad/suspensión/prescripción. No establece los límites claros entre el procedimiento de mediación y el judicial.

6.5. Sombrero verde: ¿Qué nuevas propuestas harías al protocolo? ¿Qué nuevas ideas incluirías?

Frente a las dificultades y riesgos percibidos con el anterior sombrero estos pensamientos se obtienen con el sombrero verde:

- Mayor concienciación mediadora de todos los agentes jurídicos. Mayor divulgación de los beneficios de la mediación.

- Unificar el criterio de derivación en solamente jueces y juezas, sin visto bueno de la Fiscalía.

- Que las personas mediadoras participen en la elección de los casos que pueden ser para mediar.

- Ser consciente de la falta de cultura jurídica relativa a la justicia restaurativa en la organización y de los prejuicios que ello genera para los operadores jurídicos que en ella trabajan.

- Describir cuáles son los fines de un proceso restaurativo para que todas las personas facilitadoras se impliquen en ello.

- Establecer unas líneas claras diferenciadoras respecto de la conformidad penal entre operadores jurídicos, tanto en su desarrollo como en relación con las consecuencias penológicas que de uno u otro debieran derivarse.

- Si nuestra práctica habitual es aquella en la cual un acuerdo de mediación va seguido de una conformidad entre los operadores jurídicos sobre los beneficios penales resultantes, entiendo esa conformidad ha de ser premiada por el esfuerzo adicional que conlleva para la persona denunciada, lo que exige un tratamiento diferenciado de una conformidad simple.

- Trabajar en la formulación del nuevo protocolo con la Fiscalía para superar la distonía actualmente existente entre su planteamiento teórico favorable a la Justicia Restaurativa y una realidad práctica no tan favorable.

- Determinar unos estándares mínimos formativos a las personas facilitadoras.

- Acordar revisiones anuales de seguimiento entre los agentes implicados.

- Remitirlo a los Colegios Profesionales relacionados con nuestra actividad para que lo difundan entre sus miembros, sobre todo a las comisiones colegiales de mediación.

- Incluir una breve reseña de su existencia en las entrevistas informativas.

- Humanizar el protocolo. Que la información que se facilite no se refiera exclusivamente a datos cuantitativos, sino también a cualitativos. Para mí sería imprescindible, por ejemplo, recoger y compartir el sentir de la gente.

- Evitar que la continuación de la tramitación del proceso interceda en el proceso restaurativo.

- Creación de puntos de información mediadora, de acciones de difusión en los operadores jurídicos y letrados.

- Reuniones de seguimiento cada seis meses con el Servicio de Atención a la Víctima, jueces y juezas, fiscales, personas mediadoras, funcionariado y otros servicios sociales.

- Obligación anual de revisión del protocolo para ver si continúa siendo adecuado con el funcionamiento del servicio, normativa, y nuevas formas de Resolución Alternativa de Conflictos. 
6.6. Sombrero azul: ¿Qué acciones, tareas facilitarían un nuevo protocolo? ¿Qué proceso llevarías a cabo para ponerlo en marcha?

De cara a la elaboración de un nuevo protocolo, los equipos profesionales de facilitación perciben con el sombrero azul, las siguientes propuestas:

- Potenciar un mayor protagonismo del Departamento de Justicia en el conocimiento y reconocimiento de los equipos, generando un mayor seguimiento multidisciplinar del nuevo protocolo.

- Poner en conocimiento no solo el Protocolo, sino la fecha de inicio de aplicación con una presentación oficial

- Nunca comenzar sin una buena puesta en marcha en el conocimiento directo de todas las personas implicadas.

- Animar y crear criterios que impliquen que el protocolo además de ordenar y regular el procedimiento de mediación, no dependa en exclusiva de la interpretación personal.

- Participar y difundir de forma directa el nuevo protocolo entre todas las personas intervinientes: jueces y juezas, magistrados y magistradas, ministerio fiscal, abogados, secretarios y secretarias y personal mediador.

- Instar a la Fiscalía a elaborar una Circular en la que se impulse el desarrollo de herramientas de justicia restaurativa en aras a cumplimentar los fines de la pena, la reparación a las víctimas y la responsabilidad constructiva de las personas ofensoras.

- Conseguir que la Fiscalía en su escrito de acusación provisional, mediante otro sí, defina qué consecuencias penológicas se derivarían de una conformidad simple, y cuáles de una conformidad premiada, entendiendo por tal aquella precedida de un proceso restaurativo con resultado de acuerdo.

- Formación interna de los mediadores y mediadoras, como garantía de profesionalidad.

- Fomentar el desarrollo de la justicia restaurativa en fase de ejecución de sentencia.

- Establecer un plan de actuación (bianual, trianual, quinquenal) en el que se describan objetivos, medios y herramientas de evaluación.

- Introducir la obligatoriedad por parte de los órganos judiciales de facilitar al SMI la resolución judicial que pone fin al proceso en aquellas causas en que se haya desarrollado un proceso restaurativo, con resultado de acuerdo.

- Una vez que esté el nuevo protocolo, que se difunda en los Juzgados (fiscales, jueces, personal funcionariado) a través de formación práctica impartida por personas mediadoras.

- Reuniones de seguimiento periódicas sobre el funcionamiento del protocolo.

- Puntos de información en los Juzgados y en los Colegios Profesionales. 


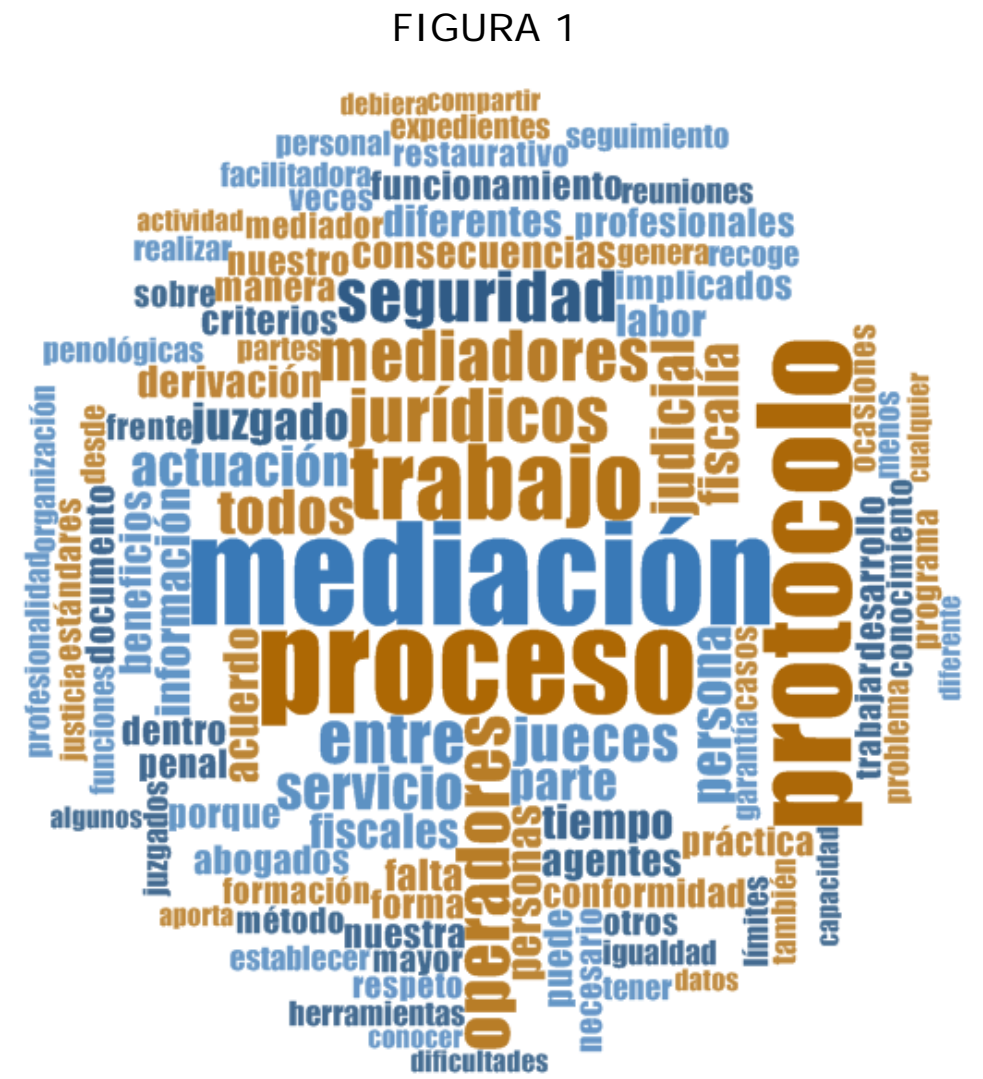

Figura 1. Marca de nube con todos los pensamientos.

(Fuente: elaboración propia.)

\section{Discusión}

La percepción, entendida como el acto y acción de percibir es “una sensación interior que resulta de una impresión material hecha en nuestros sentidos". 22

Los equipos de profesionales, con una dinámica grupal pausada han tenido la oportunidad de reflexionar y de rastrear en sus sensaciones interiores. El trabajo se ha realizado de forma ordenada y buscando el mayor número de pensamientos desde un estilo de facilitación no directiva y generando una atmósfera de escucha mutua competente.

Los equipos tienen una visión generalmente positiva de la existencia de un protocolo en el ámbito penal que otorga formalidad a su tarea profesional - no legislada-, se sienten de alguna manera parte del sistema de justicia penal, del que históricamente no han formado parte, y perciben que el protocolo de funcionamiento ofrece garantías a la ciudadanía que es derivada a procesos restaurativos por las autoridades judiciales.

Sin embargo, la convivencia de un sistema, el de justicia restaurativa, con el de justicia penal requiere importantes dinámicas de colaboración, diálogo y continua comunicación para que ambos sistemas no se den la espalda o sencillamente el más grande no se coma al más pequeño y se ofrezca una atención de calidad a la ciudadanía. ${ }^{23}$

Los juzgados, con su potente inercia burocrática, impulsan una dinámica que es percibida, en algunos casos, como amenazadora a la tarea restaurativa por parte de los equipos profesionales. Los plazos para realizar un proceso restaurativo, el escaso reconocimiento penológico a los esfuerzos restaurativos de las partes, así como la

22 Fuente: Diccionario de la lengua española de la Real Academia Española, consulta http://dle.rae.es/?id=SX9H]y3 [Acceso: 02/09/2018].

${ }^{23}$ Véase en este sentido las recomendaciones para la convivencia de ambos sistemas: Olalde 2017. 
derivación de casos calificados de "imposibles" o el fácil olvido de la existencia del propio protocolo son elementos críticos a tener en cuenta.

La convivencia de ambos sistemas no parece cómoda. Es fácil observar que un sistema como el de justicia penal, con su historia, dinámicas y lógicas punitivas confronta la realidad de otro que busca la humanización, la reparación a las víctimas y la resocialización de las personas que cometen daños contra otras. ${ }^{24} \mathrm{Y}$ resulta igualmente fácil advertir cómo pueden pervertirse los valores y principios de la justicia restaurativa, si el sistema de justicia penal se impone con sus lógicas punitivas. Muchos de los pensamientos de los equipos profesionales denotan la dificultad de esta convivencia entre autoridades judiciales y equipos de justicia restaurativa, que sólo puede abordarse con un diálogo cercano, sereno, periódico y liderado por el poder ejecutivo -como agente terciario-, en este caso el Departamento de Justicia del Gobierno Vasco.

El sombrero blanco nos ofrece una mirada más objetiva a lo que es el protocolo, destacando las palabras guía, marco de actuación, normativa, límite, hoja de ruta, garantía.

El sombrero rojo destaca por percepciones de seguridad, profesionalidad, rigidez, privilegio, soledad, frustración, incompleto e inseguridad.

El sombrero amarillo nos ofrece con su mirada positiva a los beneficios, percepciones de respeto a la legalidad, orden de actuación, seguridad, pautas necesarias para el trabajo, profesionalidad, conocimiento de las funciones de cada actor, claridad, método y respeto a unos principios de igualdad.

El sombrero negro, con su visión crítica y visibilizadora de las dificultades, problemas y riesgos, es cuantitativamente el segundo en volumen de respuestas, con una percepción de dificultades vinculadas a obstáculos puestos en marcha por las autoridades judiciales, por la subjetividad en criterios de derivación, lo obsoleto del propio protocolo tras varios años de práctica, y el amplio margen de interpretación que deja en manos de jueces y fiscales los acuerdos de las partes. Se destaca la ausencia de referencia a un estatuto de la persona facilitadora y las profundas dificultades para respetar el principio de igualdad y seguridad jurídica. El desconocimiento de los nuevos operadores jurídicos que llegan a los juzgados, o los tiempos escasos de ejecución (dos meses más uno de ampliación) son pensamientos negativos que ampliamente se repiten.

El sombrero verde, el de las nuevas ideas y soluciones a los problemas planteados, es el cuantitativamente más representativo de todos los pensamientos vinculados a los seis sombreros. Predominan pensamientos de búsqueda de caminos colaboradores entre los agentes del propio sistema de justicia penal y el sistema de justicia restaurativa. Destaca la necesidad de una mayor concienciación en los operadores jurídicos sobre los procesos restaurativos, así como sus potenciales beneficios, la necesidad de proponer espacios donde la palabra y experiencia de los equipos profesionales de justicia restaurativa sea escuchada. Ello redundará en superar el desconocimiento sobre su práctica. Se percibe la necesidad de mejorar la claridad de las consecuencias penológicas, de establecer líneas claras diferenciadoras de la conformidad. Las dinámicas de reuniones colaborativas, de seguimiento y comunicación entre sistemas, están igualmente presentes.

\section{Conclusiones}

La justicia restaurativa, entendida como cualquier proceso que permite a aquellas personas perjudicadas por el delito y aquellas responsables de dicho daño, si así lo consideran libremente, participar en el abordaje de los asuntos derivados del delito, a través de la ayuda de una tercera persona capacitada e imparcial, la persona

${ }^{24}$ Como señala Elizabeth M. Elliott, el complejo viaje de la razón a la emoción, de la formalidad a la flexibilidad, de lo jurídico a lo relacional, o de la ética de los principios a la del cuidado (Elliott 2011). 
facilitadora (Recomendación 2018(8) del Comité de Ministros del Consejo de Europa), ha llegado a la justicia penal para quedarse. ${ }^{25}$

Su desarrollo, su fuerza y su capacidad de incardinarse dentro o fuera del proceso penal en España es un reto procesal todavía por afrontar. El protocolo de funcionamiento del Servicio de Mediación Intrajudicial de Euskadi de 2017, con todas la reticencias que se quieran añadir, ha demostrado la posibilidad de desarrollar un contexto de colaboración entre operadores judiciales y equipos de facilitadores y facilitadoras para la prestación de lo que hoy se reconoce como un derecho de las víctimas, el derecho a la justicia restaurativa. ${ }^{26}$

Este artículo ha pretendido acercarse a la percepción de los profesionales de la justicia restaurativa en Euskadi, desde una perspectiva novedosa, a través de una mirada operativa con sombreros de diferente color, que nos ayuda a separar el pensamiento y desarrollar la creatividad.

Se han recogido casi 200 pensamientos individuales, pertenecientes a 14 trabajadores y trabajadoras de los servicios de mediación intrajudicial de Euskadi.

En ellos predomina una visión positiva de la existencia del protocolo, de las posibilidades que ha abierto para realizar procesos restaurativos en un contexto de colaboración entre diferentes agentes (judiciales, fiscalía, operadores jurídicos, abogacía, etc.). Sin embargo un protocolo como este requiere de innumerables esfuerzos de colaboración, diálogo y respeto mutuo para que la calidad de los servicios prestados no se vea mermada.

La existencia de este acuerdo de funcionamiento demuestra las posibilidades que tiene el desarrollo de la justicia restaurativa. Y abre a nuestro juicio, la incógnita de cómo puede ser la mejor manera de regular el desarrollo de la justicia restaurativa, o incluso si esta regulación fuera necesaria. La reciente Recomendación 2018(8) del Consejo de Ministros relativa a la justicia restaurativa en asuntos penales nos hace ver la necesidad de reglamentos especiales y salvaguardas legales que regulen su participación en el ordenamiento jurídico. No es objeto de este artículo hacer recomendaciones legales, pero sí poner en valor una dinámica de consenso y respeto entre actores que, aun con deficiencias importantes, ha abierto camino en la práctica de la justicia restaurativa en los palacios de justicia de Euskadi.

Observamos que durante los primeros años del Servicio de Mediación Penal de Barakaldo, a través de la Dirección de Justicia del Gobierno Vasco se organizaban encuentros periódicos para dialogar sobre la idiosincrasia, las dificultades, los éxitos y los fracasos de la incardinación del proceso restaurativo dentro de la lógica procesal penal. Ese es un modelo ideal de trabajo, un contexto de colaboración y diálogo periódico que permite confrontar ideas, dirimir conflictos y generar sinergias de trabajo conjunto y respetuoso a los valores de cada sistema. Más si cabe, cuando todavía su entrada en la ley de enjuiciamiento criminal no es una realidad. Esta percepción ha sido muy importante para los equipos de justicia restaurativa investigados.

Los riesgos de la institucionalización de la justicia restaurativa han sido percibidos por los equipos de justicia restaurativa, cuando observan que en ocasiones, los intereses del sistema de justicia penal se colocan por encima de los intereses y necesidades de las personas participantes. La convivencia sin duda, es compleja. Como ejemplo, están los plazos rígidos de intervención, la diferente adaptación de los acuerdos de las personas participantes en los procesos judiciales, o los continuos olvidos que algunos agentes del propio sistema judicial - en muchos ocasiones, por

\footnotetext{
${ }^{25}$ Aunque es evidente que el sistema de justicia penal no es el único donde la justicia restaurativa puede desarrollarse. Véase como ejemplo, la existencia de más de 90 agencias de base comunitaria que prestan servicios de justicia restaurativa en la provincia canadiense de Columbia Británica (Restorative Justice Victoria 2018). O la experiencia desde el ámbito universitario del Laboratorio de Teoría y Práctica de Justicia Restaurativa del Instituto Vasco de Criminología de la UPV-EHU (IVAC-KREI 2018).

${ }^{26}$ Véase la Ley 4/2015, de 27 de Abril, del Estatuto de la víctima del delito.
} 
la gran movilidad de jueces y juezas- hacen de la propia existencia del Servicio de Mediación Intrajudicial y por ende, de la justicia restaurativa.

Otros ejemplos de esta difícil convivencia revelan conflictos expresados por los y las profesionales del servicio objeto de nuestra investigación. Dichos conflictos no hacen sino reafirmarnos en la necesaria colaboración y diálogo:

- El Juzgado invita al proceso restaurativo en la propia sala, en un contexto comunicativo que es percibido por víctimas y personas ofensoras como algo coercitivo y deshumanizante: "no te lo explican, te lo dicen casi gritando, con malas formas, o con tono amenazante..." son palabras que se escuchan en la sala de mediación;

- El Juzgado realiza un diagnóstico de la mediabilidad del caso, en aras a determinadas garantías y en perjuicio de la valoración de las propias partes; ${ }^{27}$

- La Fiscalía exige una responsabilización tácita de los hechos a las personas investigadas, impidiendo que el propio proceso restaurativo sea un proceso en sí mismo que genere e incremente la responsabilización.

- Esta decisión de la Fiscalía olvida que el propio proceso restaurativo puede contribuir a la responsabilización cuando las partes se escuchan y son capaces de empatizar con el dolor. Cuando una víctima narra ante la persona ofensora su dolor y sufrimiento, se produce una dinámica humanizadora que en la mayoría de las ocasiones contribuye a una toma de conciencia del daño y una conducta de responsabilidad mucho mayor que antes de escuchar el relato de dolor. Y la víctima puede estar dispuesta a entrar en el proceso, sabiendo que quien le haya podido hacer daño no asume previamente su responsabilidad.

Los resultados obtenidos y las diferentes evaluaciones internas y externas realizadas a lo largo de estos 11 años nos ofrecen datos alentadores y escenarios de gran humanización en contextos de profundo dolor humano. El camino restaurativo no ha hecho más que empezar, pero es ilusionante para quienes creemos en una justicia penal más humana y sensible.

Probablemente la regulación sea un paso necesario para que la justicia restaurativa tenga un lugar dentro de los palacios de justicia. Sin embargo esta tarea, no debería hacerse a espaldas de los equipos de justicia restaurativa, pues su trabajo merece un respeto y su existencia un importante hito en la historia de la justicia penal. Todos y todas sabemos que el mundo jurídico tiende a promover diálogos y análisis exclusivamente jurídicos, pero las interpretaciones monocolores, han dejado de tener sentido en este mundo contemporáneo complejo. La interdisciplinariedad y la pluralidad de visiones es una oportunidad de alcanzar la verdad de lo que ocurre cuando una persona es victimizada por otra y de las necesidades que brotan de ese hecho.

\section{Referencias}

Administración de Justicia en Euskadi, 2008-2017. Documentos relacionados de justicia restaurativa [en línea]. Disponible en:

https://www.justizia.eus/justicia-restaurativa/documentos [Con acceso el 24 de junio de 2018].

Beristain, A., 1998. Criminología y victimología: alternativas re-creadoras al delito. Bogotá: Leyer.

Braithwaite, J., 2003. The fundamentals of restorative justice. En: S. Dinnen, ed. (with A. Jowitt and T.N. Cain), A Kind of Mending: Restorative Justice in the Pacific Islands [en línea]. Canberra: Pandanus Books, pp. 35-43. Disponible

\footnotetext{
${ }^{27}$ Como se señala en la Guía para la práctica de la mediación (Consejo General del Poder Judicial 2016).
} 
en: http://doi.org/10.22459/KM.11.2010 [Con acceso el 3 de diciembre de 2018].

Casado Coronas, C., 2008. Justícia restaurativa. Curs de formació de mediadors. Trànsit projectes i Ceps projectes socials. Inédito.

Castañón Álvarez, M.J., y Solar Calvo, M.P., 2016. Estatuto de la víctima: consideraciones críticas a la nueva Ley 4/2015. Diario La Ley, no 8685.

Consejo General del Poder Judicial, 2013. Guía para la práctica de la mediación intrajudicial. Madrid: Consejo General del Poder Judicial.

Consejo General del Poder Judicial, 2016. Guía para la práctica de la mediación intrajudicial [en línea]. Madrid: Consejo General del Poder Judicial. Disponible en:

http://www.poderjudicial.es/stfls/CGPJ/MEDIACI\%C3\% 93N/FICHERO/201611 08\% 20GU\% C3\% 8DA\% 20PARA\% 20LA\% 20PR\% C3\% 81CTICA\% 20DE\% 20LA\% 20MEDIACI\% C3\% 93N\% 20INTRA] UDICIAL..pdf [Con acceso el 3 de diciembre de 2018].

Council of Europe European Commission for the Efficiency of J ustice, 2007.

Guidelines for a Better Implementation of the Existing Recommendation

Concerning Mediation in Penal Matters [en línea]. 7 de diciembre.

Estrasburgo: Consejo de Europa. Disponible en:

https://rm.coe.int/1680747759 [Con acceso el 3 de diciembre de 2018].

Cutrona, C., 2014. Community mediation in the United States. En: J.M. Fritz, ed., Moving Toward a Just Peace: The Mediation Continuum. Cincinnati, $\mathrm{OH}$ : Springer, pp. 69-90.

Dandurand, Y., y Griffiths, C.T., 2006. Handbook on Restorative J ustice Programmes (Sales No. E.06.V.15) [en línea]. Viena: Oficina de las Naciones Unidas contra la Droga y el Delito. Disponible en:

https://www.unodc.org/pdf/criminal_justice/Handbook_on Restorative_Justic e Programmes.pdf [Con acceso el 3 de diciembre de 2018].

De Bono, E., 1988. Seis sombreros para pensar. Barcelona: Granica.

Departamento de Administración Pública y Justicia del Gobierno Vasco, 2014.

Servicio de Mediación Intrajudicial: SMI. Mediación penal. Memoria 2013 [en línea]. Disponible en:

https://www.justizia.eus/servlet/Satellite?blobcol=urldata\&blobheader=applic ation \% 2Fpdf\&blobheadername1 =Content-

Disposition\&blobheadervalue1=filename\% 3DMEMORIA_SMI _-

Mediaci\% C3\%B3n Penal_-

$2013 \% 282 \% 29$. pdf\&blobkey $=$ id\&blobtable=MungoBlobs\&blobwhere $=12905$ 10415378\&ssbinary=true [Con acceso el 3 de diciembre de 2018].

Departamento de Trabajo y Justicia del Gobierno Vasco, 2018. Resolución de 18 de Mayo del Director de Servicios por la que se adjudica el contrato administrativo de servicios de ejecución de las prestaciones correspondientes al Servicio de Justicia Restaurativa (Expediente A-011-DTJ-2017) [En línea]. Vitoria-Gasteiz: Gobierno Vasco, 27 de agosto. Disponible en:

http://www.euskadi.eus/gobierno-vasco/-

Lontenidos/anuncio contratacion/expx74j28275/es_doc/es arch_expx74j282 75.html [Con acceso el 7 de octubre de 2018].

Elliott, E.M., 2011. Security, with Care: Restorative J ustice and Healthy Societies. Black Point, NS: Fernwood.

Etxebarria Zarrabeitia, X., y Olalde Altarejos A.J ., 2018. Propuesta de protocolo de coordinación interinstitucional para el Servicio Vasco de Justicia Restaurativa. Asociación Konponarazle. Inédito. 
Gaddi, D., 2018. Condiciones para la evolución del paradigma restaurativo y mecanismos de su aplicación en justicia juvenil según la normativa. Revista La Trama [en línea], no 56. Disponible en:

http://www. revistalatrama.com.ar/contenidos/larevista_articulo.php?id=373\& ed=56 [Con acceso el 3 de diciembre de 2018].

García Herrera, A., 2015. Justicia restaurativa: breve reflexión sobre su integración en el marco del proceso penal en España. Diario La Ley, no 8654.

Gustafson, D.L., 2018. Encountering "the Other": Victim-Offender Dialogue in Serious Crime. Disertación de doctorado, Universidad de Lovaina.

Igartua, I., 2015. Justicia penal restaurativa y justicia penal negociada, retórica y práctica. Estudio empírico del programa de mediación intrajudicial penal en Bizkaia [en línea]. Tesis doctoral, Ciencias Sociales y Jurídicas. Leioa: Universidad del País Vasco / Euskal Herriko Unibertsitatea. Disponible en: http://hdl.handle.net/10810/15970 [Con acceso el 3 de diciembre de 2018].

Igartua, I., et al., 2015. Evaluación del coste de la justicia restaurativa integrando indicadores cuantitativos y cualitativos: El caso de la mediación penal aplicada a las infracciones de menor gravedad (Álava, 2013) [en línea]. Departamento de Administración Pública y Justicia del Gobierno Vasco. Vitoria-Gasteiz: Servicio Central de Publicaciones del Gobierno Vasco. Disponible en: http://www.poderjudicial.es/stfls/CGPJ/MEDIACI\% C3\% 93N/PUBLICACIONES/ 20170214\% 20COSTE_JUSTICIA_DEFINITIVO_PUBLICADO_G_V_09-022016 2.pdf [Con acceso el 3 de diciembre de 2018].

Instituto Vasco de Criminología-Kriminologiaren Euskal Institutua, 2018. Laboratorio de teoría y práctica de la justicia restaurativa del Instituto Vasco de Criminología [en línea]. Disponible en https://www.ehu.eus/es/web/ivac/sarrera [Con acceso el 12 de junio de 2018].

Ley $4 / 2015$, de 27 de abril, del Estatuto de la víctima del delito. Boletín Oficial del Estado [en línea], no 101, del 28 de abril de 2015. Disponible en: https://www. boe.es/buscar/doc.php?id=BOE-A-2015-4606 [Con acceso el 3 de diciembre de 2018].

Maglione, G., 2018. Pushing the theoretical boundaries of restorative justice. Nonsovereign justice in radical political and social theories. En: T. Gavrielides, ed., Routledge International Handbook of Restorative J ustice. Nueva York: Routledge.

Mate, R., 2003. Memoria de Auschwitz: actualidad moral y política. Madrid: Trotta.

McGill, D., 2017. Different Violence, Different Justice? Taking Structural Violence Seriously in Post-Conflict and Transitional Justice Processes. State Crime [en línea], 6(1), 79-101. Disponible en: https://doi.org/10.13169/statecrime.6.1.0079 [Con acceso el 3 de diciembre de 2018].

Ministerio de Justicia de España, 2013. [Borrador de Código Procesal Penal] [en línea]. Disponible en: https://moreana.es/wpcontent/uploads/2013/10/Propuesta-de-Co\% C2\% A6\% C3\%BCdigo-ProcesalPenal-2013.pdf [Con acceso el 5 de diciembre de 2018].

Olalde Altarejos, A.J., 2017. 40 ideas para la práctica de la justicia restaurativa en la jurisdicción penal. Madrid: Dykinson.

Recomendación Rec (2018) 8 del Comité de Ministros a los Estados Miembros sobre la justicia restaurativa en asuntos penales. Adoptada por el Comité de Ministros del Consejo de Europa el 3 de octubre de 2018. 
Restorative J ustice Victoria, 2018. Collaboration and capacity building in victim services and restorative justice [en línea]. Curso. Disponible en:

https://rjvictoria.thinkific.com/courses/collaboration-and-capacity-building-inrestorative-justice-and-victim-services [Con acceso el 14 de agosto de 2018].

Richards, K., 2014. A promise and a possibility: The limitations of the traditional criminal justice system as an explanation for the emergence of restorative justice. Restorative Justice: An International J ournal [en línea], 2(2), 124141. Disponible en: https://doi.org/10.5235/20504721.2.2.124 [Con acceso el 3 de diciembre de 2018].

Rosenblatt, F., 2014. Um olhar crítico sobre o papel da comunidade nos processos restaurativos. Sistema Penal \& Violen̂ncia [en línea], 6(1), 43-61. Disponible en:

http://revistaseletronicas.pucrs.br/ojs/index.php/sistemapenaleviolencia/articl e/view/16915 [Con acceso el 3 de diciembre de 2018].

Sáez Rodríguez, C., 2011. Mediación penal. Conclusiones de las experiencias en España, 1998-2011. Cuadernos penales J osé María Lidón, 8, 127-190.

Sáez Valcárcel, R., 2011. Mediación penal. Reconciliación, perdón y delitos muy graves. La emergencia de las víctimas. Cuadernos penales José María Lidón, 8, 71-125.

Sampedro-Arrubla, J., 2010. La justicia restaurativa: una nueva vía, desde las víctimas, en la solución al conflicto penal. International Law: Revista Colombiana de Derecho Internacional [en línea], 17, 87-124. Disponible en: http://revistas.javeriana.edu.co/index.php/internationallaw/article/view/1382 1/11115 [Con acceso el 3 de diciembre de 2018].

Subijana Zunzunegui, I, 2012. El paradigma de humanidad en la justicia restaurativa. Eguzkilore [en línea], 26, 143-153. Disponible en: https://www. ehu.eus/documents/1736829/2177136/Subijana+Eguzkilore+26 -16.pdf [Con acceso el 3 de diciembre de 2018].

Subijana, I.J., Porres I., y Sánchez, M., 2015. El modelo de justicia restaurativa: Una propuesta de aplicación tras la entrada en vigor de la ley 4/2015 del estatuto de la víctima. Revista de Victimología [en línea], no 2, 125-50. Disponible en: http://www. huygens.es/journals/index.php/revista-devictimologia/article/view/26 [Con acceso el 3 de diciembre de 2018].

Van Ness, D.W., 2005. An overview of restorative justice around the world [en línea]. Artículo de workshop. Bangkok: 11th United Nations Congress on Crime Prevention and Criminal J ustice. Disponible en: https://assets.justice.vic.gov.au/njc/resources/c4518c8a-c200-4623-afd142e255b62cf9/01+an+overview+of+restorative+justice.pdf [Con acceso el 3 de diciembre de 2018].

Varona Martínez, G. (con L. Vozmediano Sanz e I. Orbegozo Oronoz), 2009. Justicia restaurativa a través de los servicios de mediación penal en Euskadi. Evaluación externa de su actividad (Octubre 2008-Septiembre 2009) [en línea]. Donostia-San Sebastián, diciembre. Disponible en:

http://www. ehu.es/documents/1736829/2153076/J usticia+restaurativa+a+tr aves+de+los+servicios+de+mediacion+penal.pdf [Con acceso el 14 de agosto de 2018].

Varona Martínez, G., 2008. Evaluación externa de la actividad del Servicio de Mediación Penal de Barakaldo (Julio-Diciembre de 2007) [en línea]. DonostiaSan Sebastián, 2 de marzo. Disponible en: http://www.jusap.ejgv.euskadi.net/r47edukia/es/contenidos/informacion/mediacion_penal/es_smp/adjuntos/IVAC- 
KREI \% 20Evaluaci\% C3\% B3n\% 202007\% 20SMP\% 20Barakaldo.2.pdf [Con acceso el 29 de abril de 2018].

Vega Dueñas, L.C., y Olalde Altarejos A.J., 2018. La justicia restaurativa como paradigma orientador de paz: los encuentros restaurativos. I cade: Revista de las Facultades de Derecho y Ciencias Económicas y Empresariales [en línea], no 103. Disponible en:

http://revistas. upcomillas.es/index.php/revistaicade/article/view/8196 [Con acceso el 3 de diciembre de 2018].

Zehr, H., 1990. Changing Lenses: A New Focus for Crime and Justice. Scottdale, PA: Herald Press.

Zehr, H., 2011. Justícia restauradora: principis i pràctiques. Barcelona: Institut Català Internacional per la Pau / I cària. 